\title{
TXR1-mediated thrombospondin repression: a novel mechanism of resistance to taxanes?
}

\author{
Renée van Amerongen and Anton Berns ${ }^{1}$ \\ Netherlands Cancer Institute, Division of Molecular Genetics and Centre of Biomedical Genetics, 1066 CX \\ Amsterdam, The Netherlands
}

The usefulness of chemotherapeutic agents for the clinical treatment of cancer relies on their toxic effects on dividing cells. While most anti-cancer drugs directly affect DNA synthesis or integrity, the vinca-alkaloids and taxanes act by disrupting the cellular microtubule network (depicted schematically in Fig. 1; for review, see Zhou and Giannakakou 2005). In addition to providing structural integrity as part of the cytoskeleton, microtubules function as the cell's freeway system by providing the infrastructure along which cargo can be transported by motor proteins such as kinesin and dynein. During cell division, microtubules are critically important for the formation of the mitotic spindle, which dictates the proper segregation of chromosomes during mitosis.

Microtubules are synthesized through the polymerization of $\alpha$ - and $\beta$-tubulin subunits on their fast-growing, or plus, ends. At the same time, they are degraded on their slow-growing, or minus, ends by the release of $\alpha / \beta$ dimers into the cytosol. The combined processes of assembly and disassembly cause microtubules to be in a state of "dynamic instability," which allows the growing or shortening of individual microtubules as required. Anti-microtubule agents exert their anti-cancer effect by disrupting normal microtubule dynamics in distinct fashions. Whereas vinca-alkaloids are able to bind to free tubulin, thereby preventing microtubule assembly and concomitant mitotic spindle formation, they cannot associate with polymerized tubulin present in microtubules. In contrast, taxanes interact with polymerized tubulin to cause microtubule stabilization. As a result, cells become overloaded with microtubules and are unable to resolve the mitotic spindle, causing a mitotic arrest or apoptosis.

Taxol, the prototype chemotherapeutic of the taxane family, was isolated in the early 1970s from Taxus brevifolia. In recent years, taxol/paclitaxel and taxotere/docetaxel, a semisynthetic taxane identified in the 1980s, have become part of standard drug treatment regimens

${ }^{1}$ Corresponding author.

E-MAIL a.berns@nki.nl; FAX 31-20-512-2011.

Article is online at http://www.genesdev.org/cgi/doi/10.1101/gad.1460806. and are widely used in the clinic to treat a variety of human malignancies, including breast, ovarian, lung, gastric, and prostate cancers. The latter two are of special interest because taxanes may prove to offer some advances in the treatment of these otherwise refractory diseases.

\section{The cytotoxic effects of taxanes}

The direct effects of taxanes on microtubule dynamics, cell-cycle arrest, and apoptosis have been subject of intensive study (Fig. 2). Although both docetaxel and paclitaxel enhance microtubule stability, in vitro and in vivo studies have revealed important differences between the two drugs (Gligorov and Lotz 2004; Zhao et al. 2005). For example, docetaxel has a much higher affinity for $\beta$-tubulin compared to paclitaxel, resulting in both increased potency and elevated cytotoxicity (Riou et al. 1992). Furthermore, whereas docetaxel affects centrosome formation in the S-phase of the cell cycle, paclitaxel disrupts mitotic spindle formation in G2/M (Hennequin et al. 1995).

Moreover, depending on drug concentration, doseschedule, and the intactness of different cell-cycle checkpoints, the outcome of drug treatment can differ substantially. Low concentrations of paclitaxel $(<10 \mathrm{nM})$ generally do not result in a G2/M arrest but instead cause cell death following aberrant mitosis, whereas higher concentrations of the drug (10-100 nM) cause a terminal G2/M arrest (Torres and Horwitz 1998; Chen et al. 2003). This arrest does not result in apoptosis unless the G2/M checkpoint is disrupted. In the latter case, cells will either apoptose during mitosis upon activation of the spindle checkpoint or following mitotic catastrophe, in which cells progress through an aberrant mitosis after which the cellular default apoptotic pathway is activated (Castedo et al. 2004). Alternatively, mitotic slippage, in which cells exit from mitosis in the absence of chromosome segregation, can result in the generation of tetraploid cells, which apoptose in the presence of an intact tetraploid checkpoint (Chen et al. 2003). When this checkpoint is incapacitated, however, mitotic slippage can give rise to aneuploid cells. Finally, very high 
A
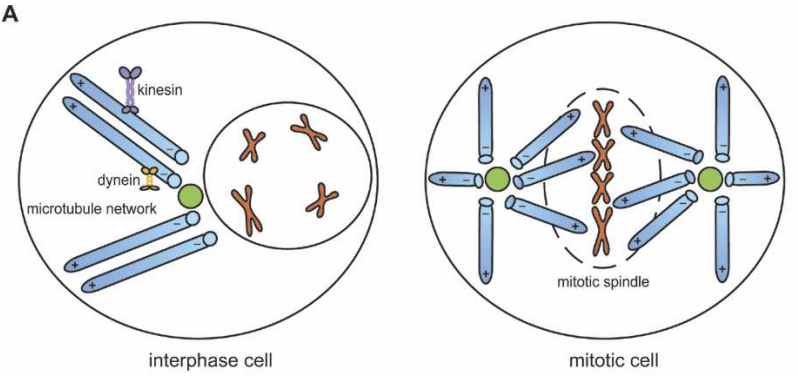

B
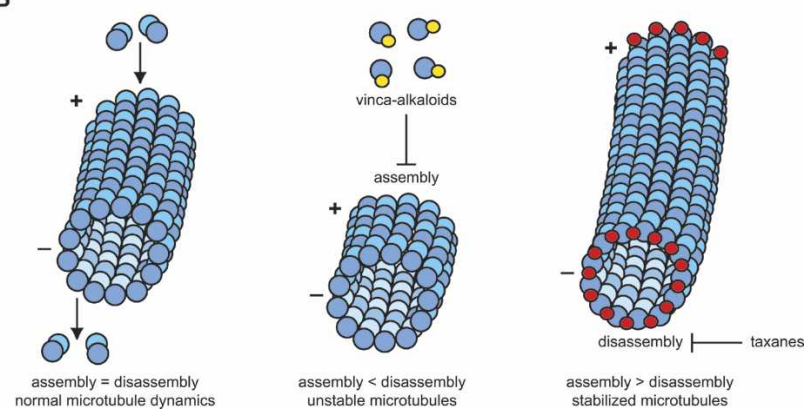

Figure 1. Microtubules are instrumental in maintaining cell viability. (A) Microtubules, which point with their plus end away from the centrosome from which they originate, have important roles during different phases of the cell cycle. In interphase, the microtubule network provides the cell with a system along which proteins, vesicles, and organelles can be transported by dedicated motor proteins. Kinesin transports cargo toward the plus end, whereas dynein walks along the microtubules toward the minus end of the microtubules. During mitosis, microtubules form the mitotic spindle, which is required for the faithful segregation of sister chromatids to opposite ends of the cell. Only after the spindle checkpoint has been passed and the spindle is properly resolved, cells are able to undergo cytokinesis to give rise to two daughter cells, each containing a diploid set of chromosomes. (B) Microtubules are highly dynamic. (Left) Microtubules can be conceived as hollow fiber-like structures, which are composed of 13 filaments. Each filament is a tubulin polymer, with alternating $\alpha$ - and $\beta$-tubulin subunits. New tubulin subunits are added to the plus end of the microtubule, whereas degradation occurs on the minus end. The regulation of both assembly and disassembly ensures proper microtubule dynamics. (Middle) Microtubule-targeting anti-cancer drugs affect the microtubule network in different ways. Vinca-alkaloids bind to $\beta$-tubulin monomers, thereby preventing them from being incorporated in growing microtubules. The balance between assembly and disassembly is distorted, and the cellular microtubule network collapses, causing mitotic failure. (Right) Taxanes, such as paclitaxel and docetaxel, have the opposite effect. Instead of preventing microtubule assembly, these drugs interact with $\beta$-tubulin that has already been incorporated into microtubules. They stabilize the structure and prevent disassembly on the minus end. As a result, cells become overloaded with microtubules, again causing a mitotic crisis.

concentrations of paclitaxel (>200 nM) cause extensive polymerization of tubulin, leading to the formation of microtubule bundles and necrosis (Yeung et al. 1999). The fact that taxane treatment has proven less beneficial for the treatment of colorectal cancer compared to other solid tumors may be related to the fact that these tumors show a high incidence of chromosomal instability and defects in cell-cycle checkpoints, the presence of which is in essence required for the cytotoxic effects of both docetaxel and paclitaxel (Swanton et al. 2006).

Different downstream events have been implicated in taxane-induced apoptosis, including the phosphorylation and concomitant inactivation of $\mathrm{Bcl} 2$, activation of JNK and Raf1, as well as both caspase-dependent and -independent apoptotic mechanisms (Zhao et al. 2005). In summary, the outcome of taxane treatment appears to be concentration-dependent and cell-type-specific, complicating the elucidation of a single mechanism that underlies the cytotoxic response to drug treatment.

\section{TXR1 activation represents a novel mechanism of taxane resistance}

As with other anti-cancer drugs, tumor cells can acquire resistance to the cytotoxic effects of taxanes. Increased drug efflux from cells through enhanced expression of the multi-drug-resistance protein P-glycoprotein-1 (PGP1) is the most frequently described mechanism (van Ark-Otte et al. 1998). Although the clinical benefit of combined therapy with taxanes and PGP1 inhibitors remains to be determined, there is evidence to suggest that the levels of PGP1 expression may be an indicator for the response to treatment (Yeh et al. 2003). Interestingly, changes in $\beta$-tubulin isotype expression, with a switch from class I to class III (Ranganathan et al. 1998; Dumontet et al. 2005; Mozzetti et al. 2005; Sève et al. 2005),

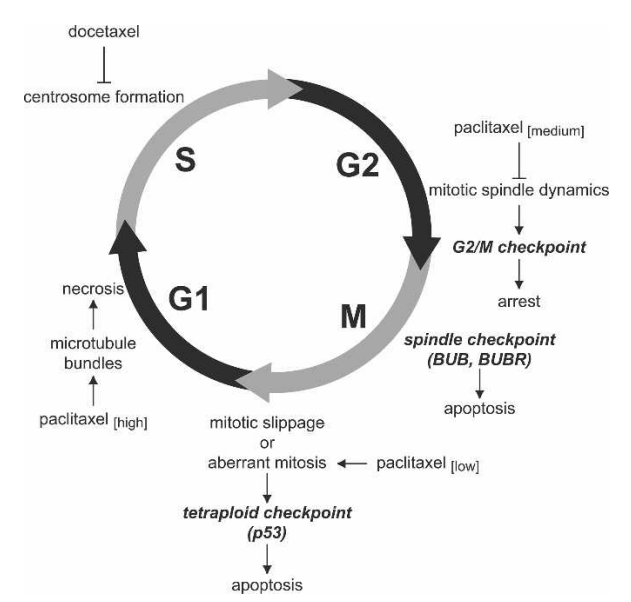

Figure 2. Taxane-induced cytotoxicity. The cytotoxic effects of taxanes do not only depend on the specific drug, but also on the concentration that is used and on the presence of cell-cycle checkpoints in the cell that is being affected. Following inhibition of mitotic spindle disassembly in G2/M, cytotoxicity requires activation of the spindle assembly checkpoint to cause a mitotic arrest. Alternatively, aberrant mitosis (with improper chromosome segregation) or mitotic slippage (an improper exit from mitosis in the absence of chromosome segregation and cytokinesis producing tetraploid cells) may occur, both of which result in apoptosis in the presence of an intact p53 checkpoint. If all cell-cycle checkpoints are incapacitated, taxane treatment may result in aneuploidism. 
have also been shown to occur upon taxane exposure, in vitro as well as in tumors from patients receiving chemotherapy. In fact, multiple studies have reported changes in isotype expression to be predictive for the outcome of taxane treatment. Mutations in the $\alpha$ - and $\beta$-tubulin genes (Giannakakou et al. 1997; He et al. 2001; Achiwa et al. 2003; Martello et al. 2003; Wang et al. 2005, 2006; Hari et al. 2006) have also been reported, although their influence on the clinical response to taxane treatment is less well established (Monzó et al. 1999; Maeno et al. 2003; Mesquita et al. 2005).

In the current issue of Genes \& Development, Lih and coworkers (Lih et al. 2006) describe a new mechanism of taxane resistance involving the novel protein TXR1, which implicates an important role for the anti-angiogenic and proapoptotic protein thrombospondin (Fig. 3). Using a modified gene-trap vector (Li and Cohen 1996), the investigators set out to search for genes that conferred resistance to paclitaxel. To this end, human prostate cancer cells infected with the gene-trap virus were grown in the presence of $10 \mathrm{nM}$ paclitaxel for $2 \mathrm{wk}$, after which a single resistant clone, 18, which showed $\sim 2.5$ fold reduced sensitivity to paclitaxel, was chosen for further study.

Insertion of the gene-trap vector results in expression

A

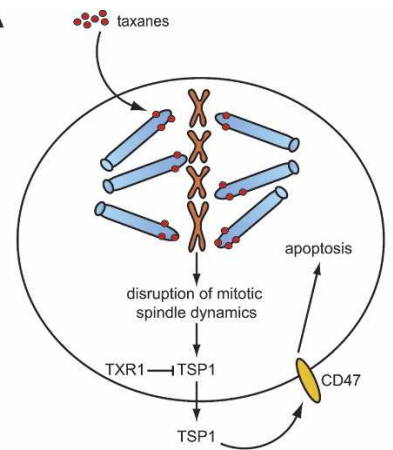

B

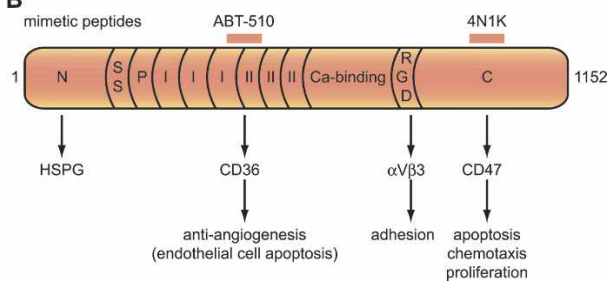

Figure 3. The multiple roles of thrombospondin. (A) Thrombospondin (TSP1) may plan an important role in the induction of apoptosis through CD47 following taxane-induced damage to the cellular microtube network. Up-regulation of TXR1 confers resistance to taxanes by repressing TSP1. (B) TSP1, which is composed of 1152 amino acids, is one of the five members of the thrombospondin family. A number of functional domains have been assigned to the protein, each of which is involved in specific biological activities. Among the known binding partners of TSP1 are heparan sulfate proteoglycans (HSPGs), integrins, and the cell surface receptors CD36 and CD47. The divergent roles of TSP1 make it a difficult protein to study, as it is likely to have different effects depending on the cell type it interacts with and the cell-surface receptors present on these cells. of an antisense transcript driven by a tetracycline-regulatable promoter, which can be expected to inhibit the expression of cellular genes in the region. Indeed, in the presence of tetracycline, sensitivity of clone 18 cells to both paclitaxel and docetaxel was restored to wild type, indicating that mere integration of the gene-trap vector had not been the cause of the observed resistance. Additional analysis showed that the gene-trap virus had landed in the 5'UTR of a novel gene, the expression of which was-quite unexpectedly and through an unknown mechanism-up-regulated about five times in cells with the insertion compared to parental cells. The investigators named the novel gene, previously identified as DKFZp564J157, TXR1, for taxol-resistance gene 1.

TXR1 encodes a small protein without any known functional domains or protein motifs. It is composed of proline residues for up to $30 \%$ and harbors a long stretch of serine residues in the C-terminal tail. In order to link TXR1 more directly to taxane resistance, the investigators used siRNA vectors directed against TXR1 to show that the reduction of TXR1 levels back to wild type in clone 18 cells restored sensitivity to paclitaxel. In addition, a reduction in TXR1 levels in the parental cells increased paclitaxel sensitivity, indicating that endogenous TXR1 may protect cells from taxane cytotoxicity. To directly show that TXR1 conferred taxane resistance, the investigators generated cells expressing exogenous TXR1 from the same tetracycline regulatable promoter as the one present in the gene trap virus, and showed that these cells indeed displayed increased resistance to paclitaxel. As the overall intracellular levels of paclitaxel were comparable in parental and clone 18 cells, drug efflux mechanisms such as PGP1 overexpression were dismissed as a possible mode of TXR1-mediated resistance. In addition, $\alpha$ - and $\beta$-tubulin expression as well as microtubule dynamics appeared to be affected to a similar extent in clone 18 and parental cells in response to paclitaxel. Both of these observations suggested that a different, more downstream event likely contributed to taxane resistance upon TXR1 activation.

\section{An unexpected role for TSP1 in taxane-induced apoptosis}

To hunt down the mechanism behind TXR1 mediated resistance to paclitaxel, Lih et al. (2006) compared microarray expression profiles of parental cells and cells harboring an activated TXR1 gene. While TXR1 itself was the most up-regulated outlier, the most prominent down-regulated gene in this analysis was thrombospondin-1 (TSP1). This inverse correlation between TXR1 and TSP1 expression was retained upon the addition of tetracycline to the cells: As TXR1 expression in clone 18 cells was reduced, the cells showed a concomitant increase in TSP1 levels back to wild type. Lih et al. were further able to show that the regulation of TSP1 by TXR1 occurred at the transcriptional level, since a luciferase reporter construct containing the TSP1 promoter was activated following tetracycline-mediated down-regulation of TXR1 expression. 
TSP1 sparked immediate interest because of its previously reported anti-angiogenic and proapoptotic activities in oncogenesis (Sid et al. 2004). In order to directly demonstrate that TSP1 mediates taxane sensitivity downstream of TXR1, the investigators administered increasing concentrations of recombinant TSP1 to clone 18 cells, thereby restoring the sensitivity to paclitaxel in these cells. In addition, after treating clone 18 cells with a combination of TSP1 and $10 \mathrm{nM}$ paclitaxel, there was an increase in the number of apoptotic cells compared to treatment with either TSP1 or paclitaxel alone. Importantly, the observed effect was specific for taxanes, since the addition of TSP1 left the cells' sensitivity to other anti-cancer drugs unaffected. Thus, TSP1 may be an effector of the apoptotic response to taxane treatment and repression of TSP1 following up-regulation of TXR1 may represent a novel mechanism of taxane resistance.

The finding that TSP1 is involved in taxane cytotoxicity is in agreement with a previous observation by (Yoo et al. 2002), who showed that docetaxel treatment of head and neck squamous cell carcinoma cell lines resulted in the induction of TSP-1. So how does TSP1, a secreted, extracellular matrix protein, directly affect cell killing by taxanes? And moreover, how can the cytotoxic effects of TSP1 be so specific to this class of anti-cancer drugs?

In a first attempt to elucidate the biological mechanism behind paclitaxel induced cell-killing through TSP1, Lih et al. (2006) directed their attention to two cell surface receptors known to mediate the TSP1 signal, CD36 and CD47, also known as integrin-associated protein (IAP). Since only the latter was expressed on their cells, they hypothesized that TSP1 was most likely to act via CD47. Indeed, when three different TSP1 mimetic peptides were added to their cells, only $4 \mathrm{~N} 1 \mathrm{~K}$, which binds to CD47, but not the mutated peptide 4NGG or ABT-510, which binds to CD36, decreased cell survival in the presence of $10 \mathrm{nM}$ paclitaxel. Conversely, inhibition of CD47 signaling by use of an anti-CD47 antibody increased cell viability in the presence of paclitaxel.

\section{Implications for chemotherapeutic intervention?}

Given the diverse effects of taxanes at different stages of the cell cycle depending on drug, dose, and cellular makeup (Fig. 2), it will be important to determine whether TSP1 is a general effector of taxane-induced cytotoxicity.

Lih et al. (2006) showed that TXR1 confers resistance to low concentrations of docetaxel and paclitaxel. As discussed above, under these circumstances, taxanes are thought to cause aberrant mitosis, which will lead to apoptosis in the presence of an intact p53-checkpoint. Since TSP1 is a known p53-target, it will be interesting to see whether TXR1 counteracts p53-mediated TSP1 activation in the presence of taxanes.

With performing their gene-trap screen by growing human prostate cancer cells in the presence of $10 \mathrm{nM}$ paclitaxel for a prolonged period of time, Lih et al., in essence, used an experimental drug treatment schedule that is reminiscent of what has become known as metronomic or low-dose chemotherapy in the clinic (Kerbel and Kamen 2004).

Chemotherapeutic regimens generally comprise the intermittent treatment with high drug doses, which not only requires prolonged intervals between cycles of treatment due to toxic side effects but which might also cause tumor cells to acquire (multi)drug resistance. In contrast, the more frequent or even continuous low-dose administration of the same chemotherapeutic agents has shown to inhibit tumor angiogenesis by targeting the nonmalignant endothelial cells of the growing tumor vasculature (Browder et al. 2000). The promise of metronomic chemotherapy is underscored by reports that tumors that have stopped responding to high-dose treatment schedules might, in some cases, still be sensitive to the same chemotherapeutic agents when these are administered in a low-dose/high-frequency schedule (Kerbel and Kamen 2004).

Metronomic chemotherapy exerts its anti-angiogenic effects by causing the up-regulation of endogenous angiogenesis inhibitors. Interestingly, one of the best-studied targets in this regard is TSP1 (Bocci et al. 2003). Of note, TSP1 levels are elevated following low-dose treatment with a range of different cytotoxic agents in addition to taxanes, suggesting that a general stress- or damage-signaling pathway results in increased TSP1 expression. The TSP1 protein contains a number of functional domains, each of which mediates one of its very diverse functions (Fig. 3B). These include binding sites for heparin sulphate proteoglycans, CD36 and CD47. In addition, TSP1 may also directly interact with integrins.

Much of what we know about the role of TSP1 in oncogenesis relates to its anti-angiogenic effects mediated by endothelial cell killing. There is ample evidence showing that, in contrast to the induction of apoptosis in tumor cells involving CD47, as described here by Lih et al. (2006), TSP1 induces endothelial cell death through CD36 (Asch et al. 1987; Dawson et al. 1997; Guo et al. 1997). This eventually results in caspase-dependent apoptosis involving p38 and JNK (Jimenez et al. 2000, 2001). A synthetic peptide, ABT-510, which is able to interact with CD36, is therefore able to mimic these anti-angiogenic activities. Both in vitro and in vivo, ABT-510 has been shown to promote CD95-mediated endothelial cell killing (Quesada et al. 2005; Yap et al. 2005). In addition, ABT-510 has been shown to synergize with cisplatin and cyclophosphamide in endothelial cell killing. Phase I clinical trials using the peptide are underway (Hoekstra et al. 2005, 2006). The observations made by Lih et al. suggest that it might be worthwhile to invest in similar studies using the 4 N1K peptide, which is able to interact with CD47.

Although Lih et al. (2006) did not investigate the mechanism of cell killing downstream of CD47, TSP1mediated CD47 activation has previously been shown to result in caspase-independent apoptosis in hematopoietic cells (Mateo et al. 1999, 2002). However, signaling through CD47 was recently also reported to augment Fas/CD95-mediated apoptosis (Manna et al. 2005), 
which proceeds through a classical, caspase-dependent pathway. In addition, CD47 mediated cell killing has also been described to proceed via a novel mechanism, which is independent of caspase and cytochrome $c$ activation but which requires cAMP activation via heterotrimeric G-proteins (Manna and Frazier 2003). The same activity might mediate the effects of TSP1 described by Lih and colleagues, as they are able to block the apoptotic response by treating the cells with pertussis toxin. Interestingly, TSP1 was recently reported to mediate caspase-independent apoptosis through CD47 in leukaemia cells in vitro, indicating that this might be a more general phenomenon in cancer cells (Saumet et al. 2005).

At this point, Lih et al. (2006) only provide in vitro data showing the importance of TSP1 for the induction of the apoptotic effect of taxanes. It is difficult, if not impossible, to extrapolate any of their findings to an in vivo situation. A recently published in vivo study describing the low-dose chemotherapeutic treatment of rats grafted with a prostatic adenocarcinoma, described the induction of TSP1 following treatment with a low dose of paclitaxel. In spite of this, no reduction in tumor weight was observed, whereas this was the case when the rats received cyclophosphamide (Damber et al. 2005). To complicate matters further, similar to the dose-dependent effects of taxanes, different doses of TSP1 have been shown to have opposing effects on cell proliferation (Isenberg et al. 2005). Thus, TSP1 is likely to have diverse effects on different cell types, depending on the presence of cell surface receptors as well as on TSP1 levels.

Clearly, it will be necessary to take a closer look at the different activities of TSP1. With regard to oncogenesis, both the anti-angiogenic effects on endothelial cells via CD36 and the proapoptotic effects on tumor cells via CD47 may have important clinical implications. If future studies support the results presented in the current study, hallmarking TSP1 as an important mediator of taxane-induced apoptosis, it might be worthwhile to explore adjuvant therapy with different TSP1 mimetic peptides as a possible way to increase the effectiveness of taxane treatment, thus not only preventing blood vessel formation but also inducing apoptosis of malignant cells. This might even allow a reduction in the doses of docetaxel or paclitaxel that are administered, thereby reducing adverse side effects such as peripheral neuropathy in addition to improving clinical outcome.

\section{Concluding remarks}

As paclitaxel and docetaxel have become part of standard chemotherapeutic regimens in the clinic, taxane resistance has become a frequently encountered phenomenon. In addition, the introduction of novel anti-microtubule agents, such as epothilones, into the clinic urges us to learn more about the biological mechanisms mediating the cytotoxic effects of these drugs.

With the risk of overextrapolating the findings made in an in vitro culture system, the results of Lih and coworkers would seem to indicate that in addition to its well-known anti-angiogenic effects, TSP1 may also have direct effects on tumor cell killing when combined with taxanes.

Additional in vivo studies using mouse model systems may be very helpful in shedding light on the combined actions of taxanes, TXR1 and TSP1, in oncogenesis. Initial studies should be directed at establishing whether the synergy between TSP1 and paclitaxel is also observed in vivo, as well as whether TXR1 also confers resistance to taxanes in an intact animal. Next, it will be important to determine whether TXR1 and TSP1 are general players in taxane resistance and taxane-induced cytotoxicity. Are their effects conserved in different tumor types? Are their effects the same in the presence of different concentrations of the drugs? Where do TXR1 and TSP1 fit into the model of what is currently known about the effects of taxanes on microtubule dynamics and mitosis? How important are the different cell cycle checkpoints for their activities? And finally, given that paclitaxel is most often used in combination with other chemotherapeutic drugs, especially with cisplatin, it would be interesting to determine whether TXR1 can also confer resistance to a combination of these agents.

Future studies will also have to be directed at unraveling the mechanism by which TXR1 causes TSP1 repression. Given its primary amino acid structure, the investigators propose a role for TXR 1 in reducing TSP1 expression through interaction with known TSP1 regulators. Although this is an attractive hypothesis, it remains to be demonstrated. It also raises the question of whether TXR1 may have a more general role in repressing transcription. Interestingly, in an attempt to generate cells overexpressing TXR1, Lih et al. (2006) were unable to obtain clones expressing TXR1 from a CMV-driven cassette. This may indicate that cells are very sensitive to the levels of TXR1 and only tolerate a very modest increase in TXR1 protein expression. This raises the question of whether high-level overexpression of TXR1 can cause cell killing or cell cycle arrest by itself, as well as whether TSP1 is involved in this. In addition to determining the precise biological roles of TXR1, it will be worthwhile to investigate whether TXR1 is overexpressed in human tumors that have acquired chemotherapeutic resistance. In any case, the data presented by Lih and coworkers tell us that we should look beyond the anti-angiogenic effects of TSP1 when it comes to treatment with taxanes, since there appears to be an unexpected role for TSP1 and CD47 in mediating paclitaxel sensitivity.

\section{Acknowledgments}

We thank Jan Schellens and Alfred Schinkel for useful suggestions and comments on the manuscript.

\section{References}

Achiwa, H., Sato, S., Shimizu, S., Maeda, H., Niimi, T., Takahashi, T., Ueda, R., and Mitsudomi, T. 2003. Analysis of 
$\beta$-tubulin gene alteration in human lung cancer cell lines. Cancer Lett. 201: 211-216.

Asch, A.S., Barnwell, J., Silverstein, R.L., and Nachman, R.L. 1987. Isolation of the thrombospondin membrane receptor. J. Clin. Invest. 79: 1054-1061.

Bocci, G., Francia, G., Man, S., Lawler, J., and Kerbel, R.S. 2003. Thrombospondin 1, a mediator of the antiangiogenic effects of low-dose metronomic chemotherapy. Proc. Natl. Acad. Sci. 100: 12917-12922.

Browder, T., Butterfield, C.E., Kraling, B.M., Shi, B., Marshall, B., O'Reilly, M.S., and Folkman, J. 2000. Antiangiogenic scheduling of chemotherapy improves efficacy against experimental drug-resistant cancer. Cancer Res. 60: 18781886.

Castedo, M., Perfettini, J.L., Roumier, T., Andreau, K., Medema, R., and Kroemer, G. 2004. Cell death by mitotic catastrophe: A molecular definition. Oncogene 23: 2825-2837.

Chen, J.G., Yang, C.P., Cammer, M., and Horwitz, S.B. 2003. Gene expression and mitotic exit induced by microtubulestabilizing drugs. Cancer Res. 63: 7891-7899.

Damber, J.E., Vallbo, C., Albertsson, P., Lennernas, B., and Norrby, K. 2005. The anti-tumour effect of low-dose continuous chemotherapy may partly be mediated by thrombospondin. Cancer Chemother. Pharmacol. 58: 1-7.

Dawson, D.W., Pearce, S.F., Zhong, R., Silverstein, R.L., Frazier, W.A., and Bouck, N.P. 1997. CD36 mediates the in vitro inhibitory effects of thrombospondin-1 on endothelial cells. J. Cell Biol. 138: 707-717.

Dumontet, C., Isaac, S., Souquet, P.J., Bejui-Thivolet, F., Pacheco, Y., Peloux, N., Frankfurter, A., Luduena, R., and Perol, M. 2005. Expression of class III $\beta$ tubulin in non-small cell lung cancer is correlated with resistance to taxane chemotherapy. Bull. Cancer 92: E25-E30.

Giannakakou, P., Sackett, D.L., Kang, Y.K., Zhan, Z., Buters, J.T., Fojo, T., and Poruchynsky, M.S. 1997. Paclitaxel-resistant human ovarian cancer cells have mutant $\beta$-tubulins that exhibit impaired paclitaxel-driven polymerization. $J$. Biol. Chem. 272: 17118-17125.

Gligorov, J. and Lotz, J.P. 2004. Preclinical pharmacology of the taxanes: Implications of the differences. Oncologist (Suppl. 2) 9: 3-8.

Guo, N., Krutzsch, H.C., Inman, J.K., and Roberts, D.D. 1997. Thrombospondin 1 and type I repeat peptides of thrombospondin 1 specifically induce apoptosis of endothelial cells. Cancer Res. 57: 1735-1742.

Hari, M., Loganzo, F., Annable, T., Tan, X., Musto, S., Morilla, D.B., Nettles, J.H., Snyder, J.P., and Greenberger, L.M. 2006. Paclitaxel-resistant cells have a mutation in the paclitaxelbinding region of $\beta$-tubulin $\left(\mathrm{Asp}^{26} \mathrm{Glu}\right)$ and less stable microtubules. Mol. Cancer Ther. 5: 270-278.

He, L., Yang, C.P., and Horwitz, S.B. 2001. Mutations in $\beta$-tubulin map to domains involved in regulation of microtubule stability in epothilone-resistant cell lines. Mol. Cancer Ther. 1: $3-10$.

Hennequin, C., Giocanti, N., and Favaudon, V. 1995. S-phase specificity of cell killing by docetaxel (Taxotere) in synchronised HeLa cells. Br. J. Cancer 71: 1194-1198.

Hoekstra, R., de Vos, F.Y., Eskens, F.A., Gietema, J.A., van der Gaast, A., Groen, H.J., Knight, R.A., Carr, R.A., Humerickhouse, R.A., Verweij, J., et al. 2005. Phase I safety, pharmacokinetic, and pharmacodynamic study of the thrombospondin-1-mimetic angiogenesis inhibitor ABT-510 in patients with advanced cancer. J. Clin. Oncol. 23: 5188-5197.

Hoekstra, R., de Vos, F.Y., Eskens, F.A., de Vries, E.G., Uges, D.R., Knight, R., Carr, R.A., Humerickhouse, R., Verweij, J., and Gietema, J.A. 2006. Phase I study of the thrombospon- din-1-mimetic angiogenesis inhibitor ABT-510 with 5-fluorouracil and leucovorin: A safe combination. Eur. J. Cancer 42: 467-472.

Isenberg, J.S., Calzada, M.J., Zhou, L., Guo, N., Lawler, J., Wang, X.Q., Frazier, W.A., and Roberts, D.D. 2005. Endogenous thrombospondin-1 is not necessary for proliferation but is permissive for vascular smooth muscle cell responses to platelet-derived growth factor. Matrix Biol. 24: 110-123.

Jimenez, B., Volpert, O.V., Crawford, S.E., Febbraio, M., Silverstein, R.L., and Bouck, N. 2000. Signals leading to apoptosisdependent inhibition of neovascularization by thrombospondin-1. Nat. Med. 6: 41-48.

Jimenez, B., Volpert, O.V., Reiher, F., Chang, L., Munoz, A., Karin, M., and Bouck, N. 2001. c-Jun N-terminal kinase activation is required for the inhibition of neovascularization by thrombospondin-1. Oncogene 20: 3443-3448.

Kerbel, R.S. and Kamen, B.A. 2004. The anti-angiogenic basis of metronomic chemotherapy. Nat. Rev. Cancer 4: 423-436.

Li, L. and Cohen, S.N. 1996. Tsg101: A novel tumor susceptibility gene isolated by controlled homozygous functional knockout of allelic loci in mammalian cells. Cell 85: 319 329.

Lih, C.-J., Wei, W., and Cohen, S.N. 2006. Txr1: A transcriptional regulator of thrombospondin-1 that modulates cellular sensitivity to taxanes. Genes \& Dev. (this issue).

Maeno, K., Ito, K., Hama, Y., Shingu, K., Kimura, M., Sano, M., Nakagomi, H., Tsuchiya, S., and Fujimori, M. 2003. Mutation of the class I $\beta$-tubulin gene does not predict response to paclitaxel for breast cancer. Cancer Lett. 198: 89-97.

Manna, P.P. and Frazier, W.A. 2003. The mechanism of CD47dependent killing of $\mathrm{T}$ cells: Heterotrimeric Gi-dependent inhibition of protein kinase A. J. Immunol. 170: 3544-3553.

Manna, P.P., Dimitry, J., Oldenborg, P.A., and Frazier, W.A. 2005. CD47 augments Fas/CD95-mediated apoptosis. J. Biol. Chem. 280: 29637-29644.

Martello, L.A., Verdier-Pinard, P., Shen, H.J., He, L., Torres, K., Orr, G.A., and Horwitz, S.B. 2003. Elevated levels of microtubule destabilizing factors in a Taxol-resistant/dependent A549 cell line with an $\alpha$-tubulin mutation. Cancer Res. 63: 1207-1213.

Mateo, V., Lagneaux, L., Bron, D., Biron, G., Armant, M., Delespesse, G., and Sarfati, M. 1999. CD47 ligation induces caspase-independent cell death in chronic lymphocytic leukemia. Nat. Med. 5: 1277-1284.

Mateo, V., Brown, E.J., Biron, G., Rubio, M., Fischer, A., Deist, F.L., and Sarfati, M. 2002. Mechanisms of CD47-induced caspase-independent cell death in normal and leukemic cells: Link between phosphatidylserine exposure and cytoskeleton organization. Blood 100: 2882-2890.

Mesquita, B., Veiga, I., Pereira, D., Tavares, A., Pinto, I.M., Pinto, C., Teixeira, M.R., and Castedo, S. 2005. No significant role for beta tubulin mutations and mismatch repair defects in ovarian cancer resistance to paclitaxel/cisplatin. BMC Cancer 5: 101.

Monzó, M., Rosell, R., Sánchez, J.J., Lee, J.S., O’Brate, A., González-Larriba, J.L., Alberola, V., Lorenzo, J.C., Núñez, L., Ro, J.Y., et al. 1999. Paclitaxel resistance in non-small-cell lung cancer associated with beta-tubulin gene mutations. $J$. Clin. Oncol. 17: 1786-1793.

Mozzetti, S., Ferlini, C., Concolino, P., Filippetti, F., Raspaglio, G., Prislei, S., Gallo, D., Martinelli, E., Ranelletti, F.O., Ferrandina, G., et al. 2005. Class III $\beta$-tubulin overexpression is a prominent mechanism of paclitaxel resistance in ovarian cancer patients. Clin. Cancer Res. 11: 298-305.

Quesada, A.J., Nelius, T., Yap, R., Zaichuk, T.A., Alfranca, A., Filleur, S., Volpert, O.V., and Redondo, J.M. 2005. In vivo 
upregulation of CD95 and CD95L causes synergistic inhibition of angiogenesis by TSP1 peptide and metronomic doxorubicin treatment. Cell Death Differ. 12: 649-658.

Ranganathan, S., Benetatos, C.A., Colarusso, P.J., Dexter, D.W., and Hudes, G.R. 1998. Altered beta-tubulin isotype expression in paclitaxel-resistant human prostate carcinoma cells. Br. J. Cancer 77: 562-566.

Riou, J.F., Naudin, A., and Lavelle, F. 1992. Effects of Taxotere on murine and human tumor cell lines. Biochem. Biophys. Res. Commun. 187: 164-170.

Saumet, A., Slimane, M.B., Lanotte, M., Lawler, J., and Dubernard, V. 2005. Type 3 repeat/C-terminal domain of thrombospondin-1 triggers caspase-independent cell death through CD47/ $\alpha \mathrm{v} \beta 3$ in promyelocytic leukemia NB4 cells. Blood 106: 658-667.

Sève, P., Mackey, J., Isaac, S., Tredan, O., Souquet, P.J., Perol, M., Lai, R., Voloch, A., and Dumontet, C. 2005. Class III $\beta$-tubulin expression in tumor cells predicts response and outcome in patients with non-small cell lung cancer receiving paclitaxel. Mol. Cancer Ther. 4: 2001-2007.

Sid, B., Sartelet, H., Bellon, G., El Btaouri, H., Rath, G., Delorme, N., Haye, B., and Martiny, L. 2004. Thrombospondin 1: A multifunctional protein implicated in the regulation of tumor growth. Crit. Rev. Oncol. Hematol. 49: 245-258.

Swanton, C., Tomlinson, I., and Downward, J. 2006. Chromosomal instability, colorectal cancer and taxane resistance. Cell Cycle 5: 818-823.

Torres, K. and Horwitz, S.B. 1998. Mechanisms of Taxol-induced cell death are concentration dependent. Cancer Res. 58: $3620-3626$

van Ark-Otte, J., Samelis, G., Rubio, G., Lopez Saez, J.B., Pinedo, H.M., and Giaccone, G. 1998. Effects of tubulin-inhibiting agents in human lung and breast cancer cell lines with different multidrug resistance phenotypes. Oncol. Rep. 5: 249255.

Wang, Y., O'Brate, A., Zhou, W., and Giannakakou, P. 2005. Resistance to microtubule-stabilizing drugs involves two events: $\beta$-tubulin mutation in one allele followed by loss of the second allele. Cell Cycle 4: 1847-1853.

Wang, Y., Yin, S., Blade, K., Cooper, G., Menick, D.R., and Cabral, F. 2006. Mutations at leucine 215 of $\beta$-tubulin affect paclitaxel sensitivity by two distinct mechanisms. Biochemistry 45: 185-194.

Yap, R., Veliceasa, D., Emmenegger, U., Kerbel, R.S., McKay, L.M., Henkin, J., and Volpert, O.V. 2005. Metronomic lowdose chemotherapy boosts CD95-dependent antiangiogenic effect of the thrombospondin peptide ABT-510: A complementation antiangiogenic strategy. Clin. Cancer Res. 11: 6678-6685.

Yeh, J.J., Hsu, W.H., Wang, J.J., Ho, S.T., and Kao, A. 2003. Predicting chemotherapy response to paclitaxel-based therapy in advanced non-small-cell lung cancer with P-glycoprotein expression. Respiration 70: 32-35.

Yeung, T.K., Germond, C., Chen, X., and Wang, Z. 1999. The mode of action of taxol: Apoptosis at low concentration and necrosis at high concentration. Biochem. Biophys. Res. Commun. 263: 398-404.

Yoo, G.H., Piechocki, M.P., Ensley, J.F., Nguyen, T., Oliver, J., Meng, H., Kewson, D., Shibuya, T.Y., Lonardo, F., and Tainsky, M.A. 2002. Docetaxel induced gene expression patterns in head and neck squamous cell carcinoma using cDNA microarray and PowerBlot. Clin. Cancer Res. 8: 3910-3921.

Zhou, J. and Giannakakou, P. 2005. Targeting microtubules for cancer chemotherapy. Curr. Med. Chem. Anticancer Agents 5: 65-71.

Zhao, J., Kim, J.E., Reed, E., and Li, Q.Q. 2005. Molecular mechanism of antitumor activity of taxanes in lung cancer (Review). Int. J. Oncol. 27: 247-256. 


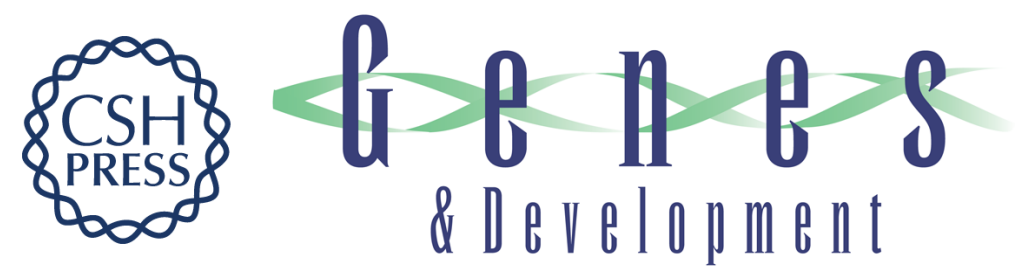

\section{TXR1-mediated thrombospondin repression: a novel mechanism of resistance to taxanes?}

Renée van Amerongen and Anton Berns

Genes Dev. 2006, 20:

Access the most recent version at doi:10.1101/gad.1460806

\section{Related Content \\ Txr1: a transcriptional regulator of thrombospondin-1 that modulates cellular sensitivity to taxanes \\ Chih-Jian Lih, Wensheng Wei and Stanley N. Cohen \\ Genes Dev. UNKNOWN , 2006 20: 2082-2095 \\ References This article cites 45 articles, 20 of which can be accessed free at: \\ http://genesdev.cshlp.org/content/20/15/1975.full.html\#ref-list-1 \\ Articles cited in: \\ http://genesdev.cshlp.org/content/20/15/1975.full.html\#related-urls \\ License \\ Email Alerting \\ Receive free email alerts when new articles cite this article - sign up in the box at the top Service

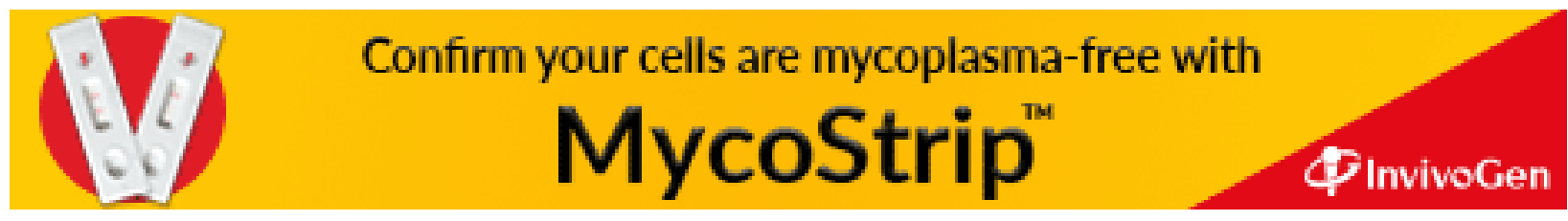

